\title{
Focal globular amyloidosis of the colon. An exceptional diagnosis
}

\author{
E. Martín-Arranz ${ }^{1}$, J. M. Pascual-Turrión ${ }^{1}$, M. D. Martín-Arranz ${ }^{1}$, E. Burgos ${ }^{2}$, C. Froilán-Torres ${ }^{1}$, L. Adán- \\ Merino $^{1}$, A. Lorenzo ${ }^{3}$ and J. M. Segura-Cabral ${ }^{1}$
}

Services of ${ }^{1}$ Gastroenterology, ${ }^{2}$ Pathology and ${ }^{3}$ Internal Medicine. Hospital Universitario La Paz. Madrid, Spain

\section{INTRODUCTION}

Globular amyloidosis is a very infrequent amyloidosis subtype, characterized by the deposition of rounded bodies of protein, occasionally perivascular instead of the usual linear deposits. The most frequently affected organ is the liver, although other organs can also been involved. To date, only eight cases (1-3) of globular amyloidosis of the gastrointestinal tract have been described. Clinical meaning of this morphologic variation of amyloidosis is unknown.

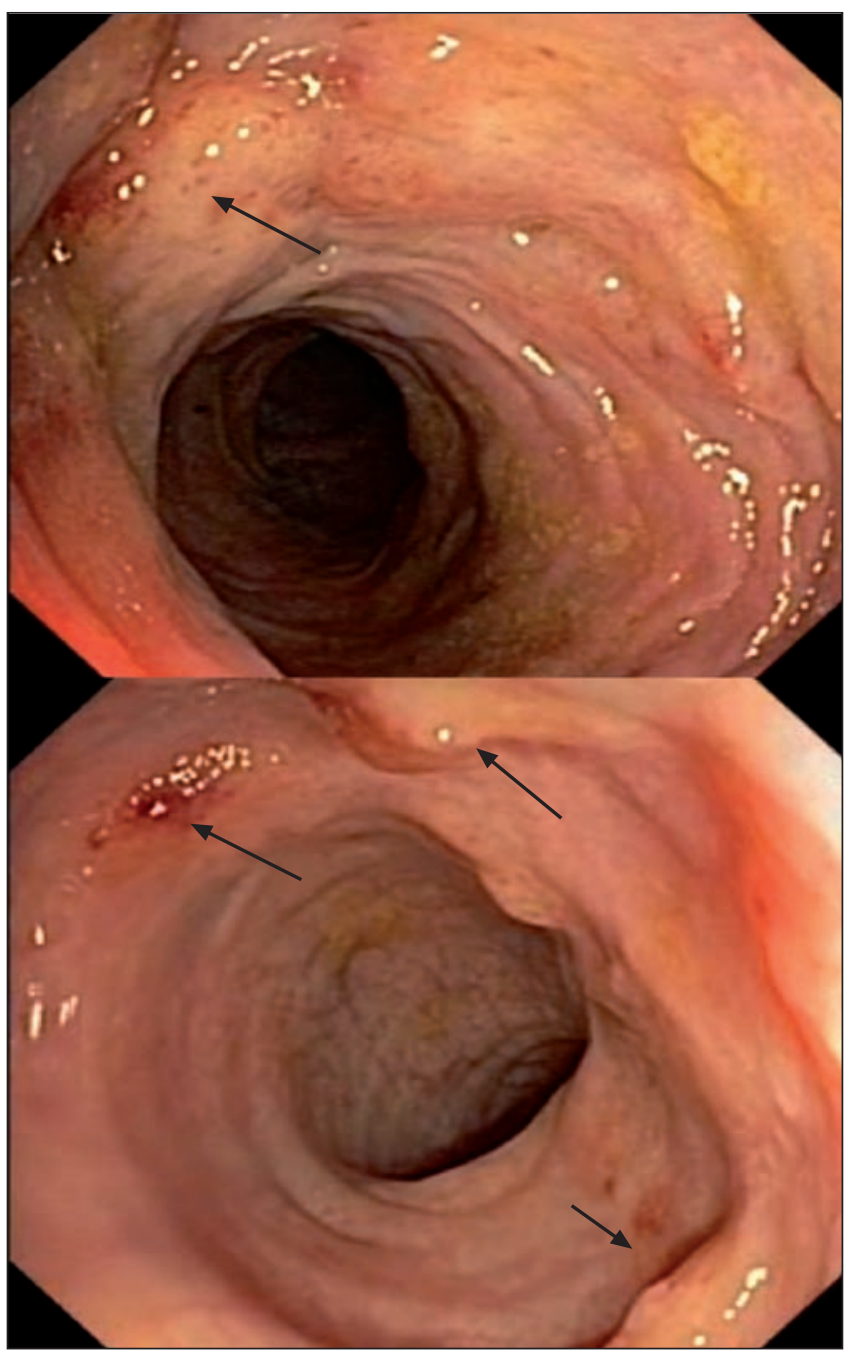

Figs. 1 y 2. Endoscopic appearance.

\section{CASE REPORT}

A 58 year old patient, with no medical history, was sent for colonoscopy because of small quantity of rectal bleeding. A rounded lesion was found in the recto-sigma junction; the biopsy was informed as unspecific inflammation. Therefore, the patient was sent to our centre for re-evaluation and to rule out malignancy. Colonoscopy discovered a soft, rounded lesion, $1 \mathrm{~cm}$ in size, with small erythematous and friable surface located in the sigmoid colon (Figs. 1 and 2). Histopathology displayed globular deposits and scanty linear collection of Congo red positive and permanganate resistant material (AL) that was informed as globular focal amyloidosis. With this diagnosis, we performed an exhaustive systemic search, but after a year of follow up the origin of this amyloid deposit is still unknown (Fig. 3).

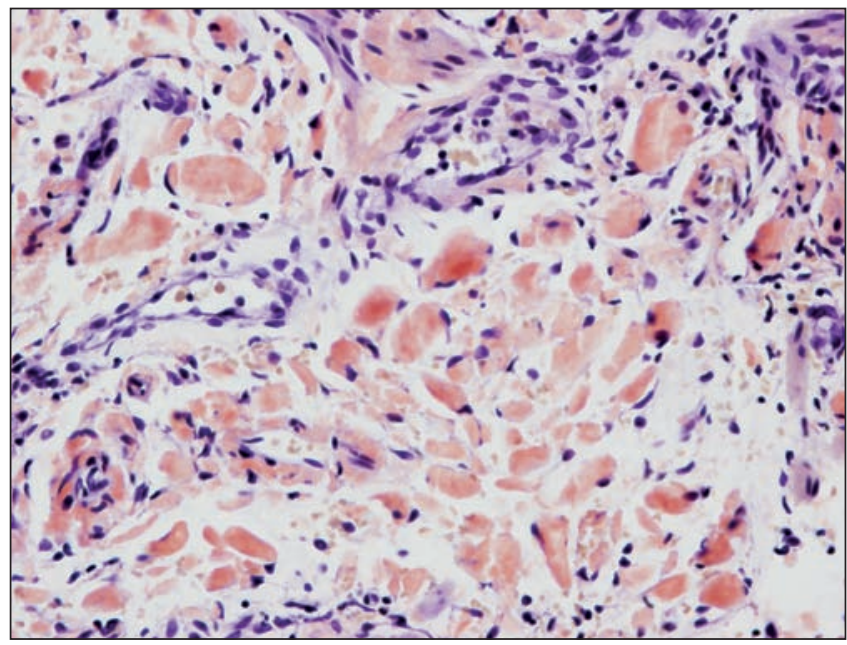

Fig. 3. Globular red Congo positive deposits. 


\section{DISCUSSION}

The presence of isolated gastrointestinal amyloidosis has been occasionally described in association of a great variety of clinical presentations, which ranges from asymptomatic to intestinal obstructions by amyloidomas. The peculiarities of the present case were its morphologic variety (globular), the immunohistochemical features (AL), and its presence as an isolated lesion. This was located in a small area of the sigmoid colon, with no predisposing illness, being, to our knowledge the second described case of globular amyloidosis in the gastrointestinal tract and the first one located in colon.

\section{REFERENCES}

1. Demirhan B, Bileziki B, Kiyici H, Boyacioglu S. Globular amyloid deposits in the wall of gastrointestinal tract: report of six cases. Amyloid 2002; 9(1): $42-6$.

2. Hemmer PR, Topazian MD, Gertz MA, Abraham SC. Globular amyloid deposits isolated to the small bowel. A rare association with AL amyloidosis. Am J Surg Pathol 2007; 31: 141-5.

3. Acebo E, Mayorga M, Val-Bernal JF. Primary amyloid tumor (amyloidoma) of the jejunum with spherical type of amyloid. Pathology 1999; 31: 8-11. 